Portland State University

PDXScholar

\title{
Divergent Interpersonal Paths to Well-Being for Insecurely Attached Emerging Adults
}

Joel A. Lane

Portland State University, lanejoel@pdx.edu

Follow this and additional works at: https://pdxscholar.library.pdx.edu/coun_fac

Part of the Counseling Psychology Commons, and the Student Counseling and Personnel Services Commons

Let us know how access to this document benefits you.

\section{Citation Details}

Lane, Joel A., "Divergent Interpersonal Paths to Well-Being for Insecurely Attached Emerging Adults" (2016). Counselor Education Faculty Publications and Presentations. 43.

https://pdxscholar.library.pdx.edu/coun_fac/43

This Post-Print is brought to you for free and open access. It has been accepted for inclusion in Counselor Education Faculty Publications and Presentations by an authorized administrator of PDXScholar. Please contact us if we can make this document more accessible: pdxscholar@pdx.edu. 
Divergent Interpersonal Paths to Well-Being for Insecurely Attached Emerging Adults

\author{
Joel A. Lane \\ Portland State University
}

Joel A. Lane, Department of Counselor Education, Portland State University.

Some of the data from this research was previously analyzed as part of a doctoral dissertation. This research was supported in part by a grant from the Association of Adult Development and Aging. The author is grateful to Drs. Patrick Johnson and Christina M. Schnyders, and Mrs. Mitsuyo Hara, for their helpful comments on previous drafts of this manuscript.

Correspondence concerning this article should be addressed to Joel A. Lane, Department of Counselor Education, Graduate School of Education, Portland State University, P. O. Box 751, 615 SW Harrison, Room 504A, Portland, OR 97207. E-mail: lanejoel@pdx.edu 


\begin{abstract}
The present study explored attachment, social support, and well-being among a sample of emerging adults. The model predicted that social support would: 1) mediate the relationship between attachment anxiety and well-being, and 2) moderate the relationship between attachment avoidance and well-being. All hypotheses were supported. Implications for counselors are discussed.

Keywords: emerging adulthood, attachment, social support, well-being
\end{abstract}


Divergent Interpersonal Paths to Well-Being for Insecurely Attached Emerging Adults In the context of Bowlby's (1969/1997) attachment theory, counseling services are more likely to be successful for individuals with elevated attachment anxiety than for those with elevated attachment avoidance (Berant \& Obegi, 2009). Multiple factors contribute to this discrepancy, including divergent trajectories in help-seeking (Vogel \& Wei, 2005), distress awareness (Fraley \& Davis, 1997), and development of therapeutic alliance (Berant \& Obegi, 2009). This discrepancy could be especially pronounced in emerging adulthood, a time in which attachment representations are increasingly projected onto non-familial relationships (Arnett, 2007; Lane, 2015). Counselors working with young adult populations would benefit from research differentiating the paths anxiously and avoidant attached emerging adults take toward developing well-being and mental health. Such research would aid professionals in improving outreach and intervention strategies for individuals with avoidant attachment patterns. Extant literature has repeatedly demonstrated the importance of social support in emerging adult wellbeing, adjustment, and transitional success (Arnett, 2007; Galambos, Barker, \& Krahn, 2006; Lane, 2015, in press-a; Larose, Guay, \& Boivin, 2002; Vogel \& Wei, 2005). However, this research has not consistently examined potential differences in the utilization of social support between specific attachment dimensions. Thus, the purpose of the present study is to examine potential differences in the intervening effects of social support on the relationships between attachment dimensions and well-being for young adults.

\section{Emerging Adult Attachment and Social Support}

The focus of attachment theory (Bowlby, 1969/1997) is the importance of early childhood relationships with caregivers in developing healthy relational functioning throughout the lifespan. Specifically, the relative quality of caregiver responsiveness to infant needs results 
in the development of expectations regarding how future needs will be met, which become internalized as representations of self and other. Consistent responsiveness to emotional and physical needs leads to positive internal representations, which aid in feeling capable and fostering healthy interpersonal relationships as adults. Conversely, inadequate care and attention may lead to an insecure attachment style, including attachment anxiety (i.e., negative self representation) and attachment avoidance (i.e., negative representation of others).

Contemporary models of adult attachment conceptualize attachment anxiety and attachment avoidance as orthogonal dimensions (Brennan, Clark, \& Shaver, 1998). A wealth of research exists supporting the importance of relative attachment security for interpersonal functioning, both in terms of social competence (e.g., Mallinckrodt \& Wei, 2005) and social support (e.g., Lane, 2015; Vogel \& Wei, 2005). As such, attachment functioning could be especially important during emerging adulthood, a time in which social support is a salient predictor of mental health and well-being (Galambos et al., 2006). Attachment security in early emerging adulthood impacts the successful transfer of attachment needs onto social networks (Schnyders \& Lane, 2015), thereby impacting perceptions of social support (Larose et al., 2002). While the transfer of attachment functioning onto peers begins in adolescence (Whiffen, 2005), it likely intensifies in emerging adulthood given that many life transitions occur during this period that decrease physical proximity to parents and caregivers (Lane, 2015).

Moreover, sources of social support are more varied and broad for today's emerging adults compared to those from prior generations (Arnett, 2007). Societal evolution and the proliferation of social media have contributed to myriad opportunities to receive support in faceto-face and online contexts (Arnett, 2007). Given the nuances and importance of social support in this stage of life, and given the contributions of attachment functioning to perceptions of social 
support (e.g., Larose et al., 2002), it is not surprising that existing emerging adult literature has identified important attachment outcomes. For example, attachment security in emerging adulthood is an important factor in promoting healthy intimacy (Scharf, Mayseless, \& KivensonBaron, 2004) and other positive psychological outcomes in emerging adulthood (Lane, 2015, in press-a, in press-b), including resilience from depressive symptoms (Whiffen, 2005), distress (Pitman \& Scharfe, 2010), and loneliness (Larose et al., 2002).

\section{Differential Effects of Attachment Anxiety and Avoidance}

While the aforementioned research highlights the importance of attachment, it does not address potential differences in the contributions of each attachment dimension (i.e., attachment anxiety and attachment avoidance) to social functioning and well-being in emerging adulthood. Contemporary theories of adult attachment functioning (e.g., Brennan et al., 1998) propose that elevated insecurity promotes one of several secondary attachment strategies in response to distress. Elevated attachment anxiety promotes hyperactive strategies, such as over-focusing on the distressing situation and relying on others for comfort. In contrast, attachment avoidance promotes deactivating strategies, resulting in inhibited awareness of distress-fueled emotions and affect (i.e., alexithymia; Fraley \& Davis, 1997). These strategies increase the likelihood of anxiously attached individuals seeking counseling and decrease the likelihood of avoidant attached individuals seeking counseling (Berant \& Obegi, 2009).

Given these different interpersonal patterns, it is possible that each attachment dimension uniquely influences the development and utilization of social support networks. Such a possibility, however, has received mixed empirical support. Some studies support congruent mediation effects, whereby the negative contributions of each attachment dimension to wellbeing are mediated by social support (Vogel \& Wei, 2005). However, other findings suggest that 
only attachment anxiety - and not attachment avoidance - is directly related to psychological distress (e.g., Whiffen, 2005). Others have found that negative expectations of parents are associated with earlier seeking of attachment needs from peers (e.g., Nickerson \& Nagle, 2005).

This possibility suggests that the two attachment dimensions may contribute to different social support-seeking trajectories in emerging adulthood. Pitman and Scharfe (2010) found support for this possibility in their work examining attachment hierarchies in emerging adulthood. Specifically, psychological distress was elevated for anxiously attached emerging adults regardless of whether they used parents or peers for support. However, avoidant attached emerging adults reported elevated distress only when relying primarily on family for support. Pitman and Scharfe concluded that emerging adults might be more motivated to rely on peer networks when their parental attachment representations are negative. Keren and Mayseless (2013) expanded upon this idea in finding that chosen attachments (i.e., peers) were more secure than unchosen attachments (i.e., family), and that attachment security increased with age (presumably because of an increasing reliance upon chosen attachments occurring throughout emerging adulthood). In tandem, these studies suggest differing support-seeking trajectories for avoidant and anxiously attached emerging adults.

A possible explanation is that social support acts as a moderator on the relationship of attachment avoidance and well-being in emerging adulthood. That is, perhaps the relationship between attachment avoidance and well-being varies with different levels of social support. Given that social support is psychologically beneficial by preventing the accumulation of stress during typically distressing situations (Sarason, Sarason, Shearin, \& Pierce, 1987), emerging adults who are low in social support could perceive more distress and engage in secondary attachment strategies (Fraley \& Davis, 1997). For individuals high in attachment avoidance, this 
would inhibit emotional awareness (Fraley \& Davis, 1997), decreasing their perceived distress and obscuring the relationship between attachment avoidance and well-being. Conversely, those with high levels of social support would be less likely to experience distress and would therefore experience a more direct relationship between attachment avoidance and well-being. This moderation effect would not be present in the case of attachment anxiety, since this attachment strategy involves the maladaptive seeking of interpersonal proximity. Thus, the contributions of social support to well-being for young adults with elevated attachment anxiety would better correspond to a mediation relationship consistent with aforementioned research.

The possibility that social support functions differently for each attachment dimension has important implications for counseling emerging adults. It would suggest that avoidant attachment strategies could be modified through cultivating positive social supports, which could have implications for perfecting service delivery methods. Thus, the present study could inform practices for improving counseling outcomes with avoidant attached emerging adults.

\section{Present Study}

To explore these possibilities, a theoretical model was developed and tested using structural equation modeling (SEM). The model predicted a theoretical sequence of relationships involving attachment anxiety, attachment avoidance, social support, and well-being among emerging adults. Specifically, the model consisted of both mediation and moderation hypotheses, such that: 1) the two attachment dimensions would negatively predict social support and wellbeing; 2) social support would mediate the relationship of attachment anxiety on well-being; and 3) social support would moderate the relationship of attachment avoidance on well-being.

\section{Method}

\section{Participants and Procedure}


The targeted population for the present study was emerging adults between the ages of 18 and 29 (Arnett, 2007) living in a large, suburban area in the Midwestern region of the United States. Email recruitment messages were sent to two listservs that reached current college students and alumni, respectively. This method allowed for the replication of the convenience sample methodology used in other prominent attachment and social support research (e.g., Mallinckrodt \& Wei, 2005; Pitman \& Scharfe, 2010), while also allowing for the findings to be more generalizable to emerging adults in general, rather than strictly current college students. Participation consisted of completing an electronic survey that was available through a link in the recruitment messages. Contained in the survey were measures of attachment orientations, perceptions of social support, and well-being. Useable data were submitted by 242 emerging adults. These data were screened using the procedures outlined by Tabachnick and Fidell (2001), resulting in the removal of five cases that were deemed multivariate outliers using Mahalanobis distance $(p<.001)$. As a result, the final study sample consisted of 237 participants. This sample size was ideal given that the theoretical model contained 23 parameters, and a 10:1 participantto-parameter ratio in SEM research is desirable for sufficient statistical power (Bentler \& Chou, 1987). The sample ranged in age from 18 to $29(M=22.93, S D=2.71)$. Participants were predominantly female $(n=172,72.6 \%)$ and Caucasian $(n=202,85.2 \%)$. Participants most commonly identified as current college students $(n=120,50.6 \%)$, while others identified as college graduates $(n=117,49.4 \%)$. ANOVA analyses confirmed that the two recruitment groups did not significantly differ with regard to any of the study variables.

\section{Instruments}

Attachment. Attachment orientation was assessed using the 12-item Experiences in Close Relationships Scale- Short Form (ECR-S; Wei, Russell, Mallinckrodt, \& Vogel, 2007). 
The items assess agreement $(1=$ strongly disagree, $7=$ strongly agree $)$ with statements related to attachment anxiety and attachment avoidance. Higher total scores for each subscale indicate higher attachment anxiety and attachment avoidance, respectively. Psychometric evaluations suggest strong construct validity and internal consistencies ranging from .77 to .86 for the anxiety subscale and .78 to .88 for the avoidance subscale (Wei et al., 2007).

Social Support. Social support was assessed using the six-item version of the Social Support Questionnaire (SSQ; Sarason et al., 1987). The items ask participants to consider all individuals from whom they seek support in certain situations (e.g., while feeling worried) and to rate their satisfaction with the available support on a six-point scale $(1=$ very dissatisfied, $6=$ very satisfied). The SSQ authors reported strong internal consistency ( $\alpha=.93)$ and test-retest reliability (.85 after 3 - to 4 -week intervals).

Well-being. The use of SEM in the present analysis offered the advantage of developing a theoretical latent variable to estimate the construct of well-being. Contemporary definitions of well-being incorporate both psychological (i.e., higher-order psychological health) and subjective (i.e., happiness) components (Lent, 2004). Psychological well-being (PWB) was assessed using the Ryff Scales of Psychological Well-Being (RSPWB; Ryff, 1989). Subjective well-being is generally thought to comprise life satisfaction, a high degree of positive affect, and a low degree of negative affect (Lent, 2004). Thus, the three indices used in addition to the RSPWB were the Satisfaction with Life Scale (SWLS; Diener, Emmons, Larsen, \& Griffin, 1985) and the Positive Affect and Negative Affect subscales of the Positive and Negative Affect Schedule (PANAS; Watson, Clark, \& Tellegen, 1988).

Ryff Scales of Psychological Well-Being (RSPWB). The RSPWB (Ryff, 1989) is a selfreport measure designed to assess a total PWB score and six subscale scores. The subscales were 
developed according to common factors from various psychological theories of healthy functioning, including autonomy, environmental mastery, personal growth, positive relations with others, purpose in life, and self-acceptance. The present study employed the 42-item version, which displays psychometric properties comparable to the full version (Springer \& Hauser, 2006). The items consist of self-statements (e.g., "I have the sense that I have developed a lot as a person over time") for which participants rate their agreement using a 6 -point scale $(1=$ disagree strongly, 6 = agree strongly). The present study utilized the total score instead of the subscale scores (Ryff, 1989; Springer \& Hauser, 2006). The total RSPWB score has high degrees of construct validity, internal consistency, and test-retest reliability (Ryff, 1989).

Satisfaction with Life Scale (SWLS). The SWLS (Diener et al., 1985) is a 5-item selfreport assessment of life satisfaction (e.g., "In most ways my life is close to my ideal"). Each item is rated on a 7 -point scale $(1=$ strongly disagree, $7=$ strongly agree $)$. The scores for each item are summed, resulting in a total score range of 5-35. Diener et al. (1985) reported an alpha coefficient of .87 and a 2-month test-retest reliability coefficient of .82 .

Positive and Negative Affect Schedule (PANAS). The PANAS (Watson et al., 1988) is a 20-item measure used to assess positive and negative affect. Each PANAS item is comprised of a single emotion word (e.g., "irritable"), and participants use a 5-point scale $(1=$ very slightly or not at all, $5=$ very $m u c h$ ) to rate the frequency with which they have experienced the emotion during the past month. The items are evenly divided between positive and negative affect, with higher scores indicate higher levels of each type of affect. Crawford and Henry (2004) reported Cronbach's alpha scores of .89 for the positive affect scale and .85 for the negative affect scale.

\section{Data Analysis}

The SEM analyses were conducted in Amos 21.0 (Arbuckle, 2012). Bias-corrected 
bootstrapping (Shrout \& Bolger, 2002) was used to estimate the parameters and test the significance of the indirect effects. This approach estimates parameters by repeatedly resampling and replacing the data set, allowing for the creation of confidence intervals for each effect. Because of bias-correction, the confidence intervals do not depend on assumptions of symmetry (Shrout \& Bolger, 2006). Indirect effects are statistically significant when 0 falls outside of the confidence interval range. The present analysis was set to execute 10,000 bootstrapped samples. Hooper, Coughlan, and Mullen (2008) recommended assessing model fit with both absolute and incremental fit indices. Thus, three common fit indices were used. Two of these indices assessed absolute fit: the Chi-Square Goodness of Fit Test $\left(\chi^{2}\right)$, in which smaller, preferably nonsignificant values are indicative of better fit, and the Root Mean Square Error of Approximation (RMSEA), in which values below .06 are indicative of good fit. The third fit index, the Comparative Fit Index (CFI), assessed incremental fit. The CFI should exceed .95 .

The analysis of the moderation hypothesis was conducted using the method outlined by Tein, Sandler, MacKinnon, and Wolchik (2004). First, a continuous attachment avoidance-social support interaction variable was created. This involved centering the two variables (i.e., subtracting the respective mean from each case to reduce multicollinearity) and multiplying the resulting values. Post-hoc analyses tested the theoretical model multiple times using three separate interaction variables. These variables used manipulated social support values centered so that 0 was equal to the mean, $-1 S D$, or $+1 S D$, respectively, allowing for comparisons to be made between low, medium, and high levels of social support.

\section{Results}

\section{Initial Covariate Analysis}

To reduce the possibility of confounds in the findings, the participant demographic 
variables of age and gender were examined for significant relationships among the study variables. The significance of these potential covariates was tested by adding them to the theoretical model: paths were drawn connecting them to both attachment dimensions, social support, and the well-being latent variable (gender was coded as a dummy variable so that $0=$ male and $1=$ female). Significant relationships involving age occurred for attachment anxiety $(\beta$ $=-.14, p<.05)$, attachment avoidance $(\beta=-.18, p<.01)$, and social support $\beta=.12, p<.05)$. That is, as age increased, so too did attachment security and social support. Additionally, gender was significantly related to attachment avoidance $(\beta=-.14, p<.05)$ and social support $(\beta=.15$, $p<.05)$. That is, being female was associated with lower attachment avoidance and higher satisfaction with social support. Accordingly, the significant parameters involving age and gender were included in all subsequent structural model analyses. The descriptive statistics and intercorrelations among instrument scales and covariates are displayed in Table 1.

\section{Structural Model Analysis}

In order to examine the utility of the full theoretical model, an initial mediation model comprised of paths nested in the full model was tested. This model was constructed by constraining to 0 all paths associated with the interaction variable, thus leaving only the mediation paths free to be estimated. As expected, this nested mediation model did not provide an adequate fit to the data: $\chi^{2}(28)=63.99, p=.000 ; \mathrm{RMSEA}=.074 ; \mathrm{CFI}=.930$.

Next, the full theoretical model (Model A) was tested by removing the constraints from the parameters connected to the interaction variable. This model provided an excellent fit to the data: $\chi^{2}(25)=34.60, p=.096 ; \mathrm{RMSEA}=.040 ; \mathrm{CFI}=.981 ;$ model fit was significantly improved compared to the nested mediation model: $\chi^{2}(3)=29.39, p<.001$. The path estimates are depicted in Figure 2. Consistent with the present hypotheses, social support was significantly 
related to well-being $(\beta=.52, p<.001)$, while attachment anxiety, attachment avoidance, and the interaction variable were each negatively related to well-being $(\beta=-.16, p<.01, \beta=-.25, p<$ .001 , and $\beta=-.16, p<.01$, respectively). While attachment anxiety was significantly related to social support $(\beta=-.36, p<.001)$, attachment avoidance was not $(\beta=-.02, p=n s)$. Thus, hypothesis 1 was only partially supported. As predicted, the mediated effect of attachment anxiety on well-being through social support was significant: $\beta=-.19, B=-.63, p<.001$, while the mediated effect of attachment avoidance on well-being through social support was not significant: $\beta=-.01, B=-.04, p=n s$. Therefore, Hypothesis 2 was fully supported.

\section{Post Hoc Interaction Analyses}

The significant, negative parameter connecting the interaction variable with well-being necessitated post-hoc analysis to determine if moderation was present. To do so, two additional models were created and compared to the primary theoretical model. Table 2 summarizes the relevant statistics for these analyses. The first of these two models (Model B) utilized a recalibrated interaction variable in which social support scores were recentered so that zero was equal to one $S D$ below its mean (Tein et al., 2004). Next, the model was tested again, but this time with an interaction variable using social support scores recentered so that zero was equal to one $S D$ above the mean (Model C). Compared to the primary model, Model B displayed a pronounced effect on the path from attachment avoidance to well-being, reducing its standardized coefficient from $\beta=-.25(p<.001)$ to $\beta=-.05(p=n s)$. That is, at lower levels of social support respective to the mean attachment avoidance score, the relationship between attachment avoidance and well-being was reduced almost to zero. In contrast, Model C revealed a strengthened path from attachment avoidance to well-being compared to Model A, increasing from $\beta=-.25(p<.001)$ to $\beta=-.44(p<.001)$. These models demonstrated that the negative 
effect of attachment avoidance on well-being increased as social support increased. It should be noted that, throughout the testing of these three models, the mediation effect of attachment avoidance on well-being through social support remained non-significant.

\section{Alternative Model Testing}

When cross-section samples are used to test hypotheses involving indirect effects, it is useful to also test models with alternative relationships among the variables of interest (Bentler \& Chou, 1987). Doing so allows for a comparison of fit between the hypothesized model and another model that could potentially explain the relationships among the study variables. Thus, two alternative models (Models D and E) were tested. Model D randomly reorganized the study variable relationships in order to evaluate the directionality of relationships in the theoretical model. Model D did not provide an adequate fit to the data: $\chi^{2}(26)=68.54, p=.000$; RMSEA $=.083 ; \mathrm{CFI}=.917$, and was significantly worse than Model A: $\chi 2(1)=33.94, p<.001$. This expected result supported the hypothesized relationships of Model A.

Model E was then tested to examine whether or not social support moderated the effects of attachment anxiety in addition to attachment avoidance. To do so, an additional interaction variable - specifically, the interaction of the mean centered attachment anxiety scores and the mean centered social support scores - was created and added to the main theoretical model. If this model provided a better fit to the data, and if the anxiety-support interaction variable significantly predicted well-being, it would undermine the main theoretical assertions informing the present study's primary theoretical model (i.e., that the intervening relationships involving attachment, social support, and well-being are unique with regard to attachment anxiety and attachment avoidance). Though Model E provided a good fit to the data, $\chi^{2}(31)=45.95, p$ $=.041 ; \mathrm{RMSEA}=.045 ; \mathrm{CFI}=.974$, each of the fit indices were worse than those of the primary 
model. The change in $\chi^{2}$ was nearly statistically significant: $\chi 2(6)=11.35, p=.078$, and the anxiety-support interaction variable was not significantly related to well-being $(\beta=-.01, p=n s)$. These results supported the present study's theoretical assumptions.

\section{Discussion}

The purpose of the present study was to develop and test a theoretical model proposing the nature of relationships among attachment dimensions, social support, and well-being for emerging adults. Specifically, the model predicted that social support would 1) mediate the negative relationship between attachment anxiety and well-being, and 2) moderate the negative relationship between attachment avoidance and well-being. The model provided an excellent fit to the data and these hypotheses were supported.

As predicted, social support seemed to moderate the relationship between attachment avoidance and well-being. Specifically, at lower levels of social support, the direct effect of attachment avoidance on well-being was virtually non-existent, while this relationship grew in magnitude as social support increased. This moderation effect supports the aforementioned possibility that low levels of social support promote distress among emerging adults, causing those with elevated attachment avoidance to engage in deactivating attachment strategies (Fraley \& Davis, 1997), which in turn clouds the accuracy of their perceptions of well-being. Conversely, those with high levels of social support may have been less deactivated and more emotionally aware, resulting in a strengthened negative relationship between attachment avoidance and well-being. While this explanation should be considered tentative pending further validation, it suggests that social support is utilized differently for young adults as a function of attachment style. That is, changing social support seemed to change the avoidance and wellbeing relationship but not the anxiety and well-being relationship. Instead, social support seemed 
to explain (rather than change) the effect of attachment anxiety on well-being.

These results provide context to the findings of the studies on which the present theoretical model was based. Pitman and Scharfe (2010), for example, found that emerging adults with elevated attachment avoidance only reported elevated distress when relying on family for support. According to attachment theory, individuals with avoidant attachment are less likely to engage in exploration activities, even if they negatively evaluate their current environments (Bowlby, 1969/1997). In emerging adulthood, leaving home and decreasing proximity to family represents a significant exploration activity associated with positive psychosocial development (Arnett, 2007). As such, emerging adults with avoidant attachment would be more likely to experience leaving home and transferring attachments as a psychologically threatening experience, which could initiate a deactivating strategy, potentially explaining Pitman and Scharfe's finding that those who relied on peers did not endorse elevated distress. Such a possibility is consistent with recent literature suggesting that normative life transitions in emerging adulthood are especially psychologically threatening since emerging adults do not subjectively identify as adults (Lane, 2013, 2015, in press-b; Weiss, Freund, \& Wiesse, 2012). That is, the transitions that commonly occur in this time period (leaving home, entering and leaving college, beginning careers) are connected to societal expectations that one is achieving an adult identity (Lane, 2013), which can be psychologically difficult for emerging adults, who subjectively identify as being 'in between' adolescence and adulthood (Arnett, 2007).

\section{Implications for Counselors}

The present results suggest that efforts to enhance social support could increase the number of emerging adults with attachment avoidance who seek counseling services. That is, social support could lead to increased emotional awareness for these individuals, which in turn 
could increase their likelihood of utilizing counseling. These findings are useful for college counselors, who routinely work with young adult populations. Because attachment avoidance is negatively related to help-seeking (Vogel \& Wei, 2005) and counseling utilization (Berant \& Obegi, 2009), the present findings support the use of initiator-catalyst approaches to college counseling services (Archer \& Cooper, 1999), whereby counselors help students through enacting non-counseling outreach services that increase the likelihood of counseling utilization. For example, prior studies have demonstrated the efficacy of college student mentoring in promoting relational health and adjustment (Lenz, 2014). In the context of the present study, mentoring programs could expose avoidant attached college students to healthy social supports, which may increase their distress awareness and lead to college counseling utilization. Thus, college counselors are encouraged to enact non-counseling outreach programs as a means of increasing counseling attendance among students high in attachment avoidance.

In the context of mental health counseling, the present findings also have implications for enhancing efficacy with attachment avoidant clients, a population that is often considered difficult to counsel. Attachment avoidance can interfere with the therapeutic alliance, as it promotes resistance to interpersonal intimacy (Berant \& Obegi, 2009). Counselors are encouraged to use the present findings to increase their empathic understanding of these individuals. That is, while client resistance and interpersonal distance often lead to difficult counseling experiences, the findings suggest that such strategies might provide a means of inhibiting distress awareness. Thus, counselors could conceptualize avoidant strategies as coping behaviors, contextualizing client behaviors that often threaten counselor self-efficacy (Iarussi, Tyler, Littlebear, \& Hinkle, 2013) and stimulate countertransference (Berant \& Obegi, 2009).

\section{Limitations}


Several limitations in the present study warrant acknowledgement. The sample was relatively homogenous with regard to gender ( $71.9 \%$ female) and ethnicity ( $85.1 \%$ white). Thus, caution is recommended in applying the results to emerging adults who are male or non-white. Additionally, it is important to note the non-experimental, cross-sectional design of the present study. While such a design resembles other prominent research exploring attachment, interpersonal functioning, and mental health (e.g., Pitman \& Scharfe, 2010), it limits the ability to make cause-and-effect assumptions about the findings. However, to address this issue, two alternative models were tested and found to be inferior to the main theoretical model. Nevertheless, the data was collected at one point in time and cannot prove causation. Finally, all of the instruments relied on self-report and, therefore, are susceptible to mono-method bias.

\section{Implications for Future Research}

Future research should work to replicate the present results with a more heterogeneous sample. Attention should also be devoted to a more complete understanding of the moderation effect involving attachment avoidance. A particularly useful next step would involve incorporating a measure of alexithymia into the present theoretical model as a means of explaining the moderation finding. This approach would offer a means of evaluating the conclusions drawn from the present findings: that low levels of social support induce distress, engaging secondary attachment strategies that - in the case of elevated attachment avoidance inhibit emotional awareness and obscure the negative relationship between attachment avoidance and well-being. Other beneficial efforts would involve assessing whether or not levels of attachment anxiety and avoidance become more secure as a result of attending counseling. Such research would validate the present findings and advance current understandings regarding attachment dimensions, social support, and well-being in emerging adulthood. 


\section{References}

Arbuckle, J. L. (2012). Amos (Version 21.0) [Computer Program]. Chicago: SPSS.

Archer, J., Jr. \& Cooper, S. (1999). An initiator-catalyst approach to college counseling outreach. Journal of College Counseling, 2(1), 76-88.

Arnett, J. J. (2007). Socialization in emerging adulthood: From the family to the wider world, from socialization to self-socialization. In J. E. Grusec \& P. D. Hastings (Eds.), Handbook of socialization: Theory and research (pp. 208-231). New York: Guilford.

Bentler, P. M., \& Chou, C.-P. (1987). Practical issues in structural equation modeling. Sociological Methods Research, 16(1), 78-117.

Berant, E., \& Obegi, J. H. (2009). Attachment-informed psychotherapy research with adults. In J. H. Obegi \& E. Berant (Eds.), Attachment theory and research in clinical work with adults (pp. 461-489). New York: Guilford.

Bowlby, J. (1997). Attachment and loss: Vol. 1. Attachment. New York: Basic Books. (Original work published 1969).

Brennan, K. A., Clark, C. L., \& Shaver, P. R. (1998). Self-report measurement of adult attachment: An integrative overview. In J. A. Simpson \& W. S. Rholes (Eds.), Attachment theory and close relationships (pp. 46-76). New York: Guilford Press.

Crawford, J. R., \& Henry, J. D. (2004). The Positive and Negative Affect Schedule (PANAS): Construct validity, measurement properties and normative data in a large non-clinical sample. British Journal of Clinical Psychology, 43(3), 245-265.

Diener, E., Emmons, R. A., Larsen, R. J., \& Griffin, S. (1985). The Satisfaction With Life Scale. Journal of Personality Assessment, 49(1), 71-75.

Fraley, R. C., \& Davis, K. E. (1997). Attachment formation and transfer in young adults' close 
friendships and romantic relationships. Personal Relationships, 4(2), 131-144.

Galambos, N. L., Barker, E. T., \& Krahn, H. J. (2006). Depression, self-esteem, and anger in emerging adulthood: Seven-year trajectories. Developmental Psychology, 42(2), 350-365.

Hooper, D., Coughlan, J., \& Mullen, M. R. (2008). Structural equation modelling: Guidelines for determining model fit. Electronic Journal of Business Research Methods, 6(1), 53-60.

Iarussi, M. H., Tyler, J. M., Littlebear, S., \& Hinkle, M. S. (2013). Integrating motivational interviewing into a basic counseling skills course to enhance counseling self-efficacy. The Professional Counselor, 3(3), 161-174.

Keren, E., \& Mayseless, O. (2013). The freedom to choose secure attachment relationships in adulthood. The Journal of Genetic Psychology, 174(3), 271-290.

Lane, J. A. (2013). Group counseling for students transitioning out of postsecondary education: A narrative approach. Groupwork: An Interdisciplinary Journal for Working With Groups, 23(1), 34-55.

Lane, J. A. (2015). Counseling emerging adults in transition: Practical applications of attachment and social support research. The Professional Counselor, 5(1), 15-27.

Lane, J. A. (in press-a). Attachment, well-being, and college senior concerns about the transition out of college. Journal of College Counseling.

Lane, J. A. (in press-b). The imposter phenomenon among emerging adults transitioning into professional life: Developing a grounded theory. Adultspan Journal.

Larose, S., Guay, F. \& Boivin, M. (2002). Attachment, social support, and loneliness in young adulthood: A test of two models. Personality and Social Psychology, 28(5), 684-693.

Lent, R. W. (2004). Toward a unifying theoretical and practical perspective on well-being and psychological adjustment. Journal of Counseling Psychology, 51(4), 482-509. 
Lenz, A. S. (2014). Mediating effects of relationships with mentors on college adjustment. Journal of College Counseling, 17(3), 195-207.

Mallinckrodt, B., \& Wei, M. (2005). Attachment, social competencies, social support, and psychological distress. Journal of Counseling Psychology, 52(3), 358-367.

Nickerson, A. B., \& Nagle, R. J. (2005). Parent and peer attachment in late childhood and early adolescence. Journal of Early Adolescence, 25, 223-249.

Pitman, R., \& Scharfe, E. (2010). Testing the function of attachment hierarchies during emerging adulthood. Personal Relationships, 17, 201-216.

Ryff, C. D. (1989). Happiness is everything, or is it? Explorations on the meaning of psychological well-being. Journal of Personality and Social Psychology, 57(6), 10691081.

Sarason, I. G., Sarason, B. R., Shearin, E. N., \& Pierce, G. R. (1987). A brief measure of social support: Practical and theoretical implications. Journal of Social and Personal Relationships, 4(4), 497-510.

Scharf, M., Mayseless, O., \& Kivenson-Baron, I. (2004). Adolescents' attachment representations and developmental tasks in emerging adulthood. Developmental Psychology, 40(3), 430-444.

Schnyders, C. M., \& Lane, J. A. (2015). Gender differences regarding parental and peer attachments in early emerging adulthood experiences. Manuscript submitted for publication.

Shrout, P. E., \& Bolger, N. (2002). Mediation in experimental and non-experimental studies: New procedures and recommendations. Psychological Methods, 7(4), 422-445.

Springer, K. W., \& Hauser, R. M. (2006). An assessment of the construct validity of Ryff's 
Scales of Psychological Well-Being: Method, mode, and measurement effects. Social Science Research, 35(4), 1080-1102.

Tabachnick, B. G., \& Fidell, L. S. (2001). Using multivariate statistics $\left(4^{\text {th }}\right.$ ed.). Needham Heights, MA: Allyn \& Bacon.

Tein, J.-Y., Sandler, I. N., MacKinnon, D. P., \& Wolchik, S. A. (2004). How did it work? Who did it work for? Mediation in the context of a moderated prevention effect for children of divorce. Journal of Consulting and Clinical Psychology, 72, 617-624.

Vogel, D. L., \& Wei, M. (2005). Adult attachment and help-seeking intent: the mediating roles of psychological distress and perceived social support. Journal of Counseling Psychology, 52(3), 347-357.

Watson, D., Clark, L. A., \& Tellegen, A. (1988). Development and validation of brief measures of positive and negative affect: The PANAS Scales. Journal of Personality and Social Psychology, 54(6), 1063-1070.

Wei, M., Russell, D. W., Mallinckrodt, B., \& Vogel, D. L. (2007). The Experiences in Close Relationship Scale (ECR)-Short Form: Reliability, validity, and factor structure. Journal of Personality Assessment, 88, 187-204.

Weiss, D., Freund, A. M., \& Wiesse, B. S. (2012). Mastering developmental transitions in young and middle adulthood: The interplay of openness to experiences and traditional gender ideology on women's self-efficacy and subjective well-being. Developmental Psychology, 48(6), 1774-1784.

Whiffen, V. E. (2005). The role of partner characteristics in attachment insecurity and depressive symptoms. Personal Relationships, 12, 407-423. 
Table 1

Descriptive Statistics and Intercorrelations among Instrument Scales

\begin{tabular}{|c|c|c|c|c|c|c|c|c|c|c|c|}
\hline \multirow[t]{2}{*}{ Variables } & \multicolumn{9}{|c|}{ Intercorrelations } & \multirow[b]{2}{*}{8} & \multirow[b]{2}{*}{9} \\
\hline & $M$ & $S D$ & 1 & 2 & 3 & 4 & 5 & 6 & 7 & & \\
\hline 1. Attachment Anxiety & 3.50 & 1.11 & .74 & $.38 * *$ & $-.38 * *$ & $-.42 * *$ & $-.35 * *$ & $-.27 * *$ & $.25^{* *}$ & $-.14 *$ & .04 \\
\hline 2. Attachment Avoidance & 2.48 & 1.09 & & .85 & $-.20 * *$ & $-.40 * *$ & $-.31 * *$ & $-.28 * *$ & $.21 * *$ & $-.16^{*}$ & -.12 \\
\hline 3. Social Support & 5.27 & 0.77 & & & .89 & $.49 * *$ & $.53 * *$ & $.41 * *$ & $-.21 * *$ & $.17 * *$ & $.13 *$ \\
\hline 4. PWB & 4.51 & 0.65 & & & & .93 & $.58 * *$ & $.62 * *$ & $-.31 * *$ & .09 & $.14^{*}$ \\
\hline 5. Life Satisfaction & 4.82 & 1.34 & & & & & .87 & $.49 * *$ & $-.37 * *$ & .06 & .10 \\
\hline 6. Positive Affect & 3.55 & 0.73 & & & & & & .87 & -.08 & -.01 & .04 \\
\hline 7. Negative Affect & 2.52 & 0.73 & & & & & & & .84 & -.08 & .02 \\
\hline 8. Age & 22.93 & 2.71 & & & & & & & & -- & -.04 \\
\hline 9. Gender & -- & -- & & & & & & & & & -- \\
\hline
\end{tabular}

Note: $N=237$. Internal consistencies $(\alpha)$ are displayed on the diagonal. All reported instrument means are item-level means, not sums of the means.

$* p<.05 . * * p<.01$. 
Table 2

Moderation Effects Involving Attachment Avoidance Predicting Well-Being

\begin{tabular}{cccccccc}
\hline Model & $\begin{array}{c}\text { Moderator } \\
\text { Variable }\end{array}$ & $\begin{array}{c}\text { Direct effect } \\
\text { of AA }(\beta)\end{array}$ & $\begin{array}{c}\text { Direct effect of } \\
\text { interaction }(\beta)\end{array}$ & $\begin{array}{c}\text { Standardized } \\
\text { indirect effect }\end{array}$ & $\begin{array}{c}\text { Mean indirect } \\
\text { effect }(B)^{\mathrm{a}}\end{array}$ & $\begin{array}{c}S E \text { of } \\
\text { mean }^{\text {a }}\end{array}$ & $\begin{array}{c}95 \% \text { confidence } \\
\text { interval }^{\text {a }}\end{array}$ \\
\hline Mediation & -- & $-.28^{* *}$ & -- & -.011 & -.036 & .101 & -.235 to .161 \\
Model A & Centered & $-.25 * *$ & $-.16^{*}$ & -.011 & -.038 & .107 & -.251 to .169 \\
Model B & Low SS & -.05 & $-.28^{* *}$ & -.010 & -.036 & .107 & -.248 to .171 \\
Model C & High SS & $-.44^{* *}$ & $-.22^{* *}$ & -.013 & -.044 & .108 & -.256 to .166 \\
\hline
\end{tabular}

Note: $\mathrm{AA}=$ attachment avoidance, $\mathrm{SS}=$ social support. ${ }^{\text {a }}$ Values based on unstandardized coefficients.

$* p<.01 . * * p<.001$. 


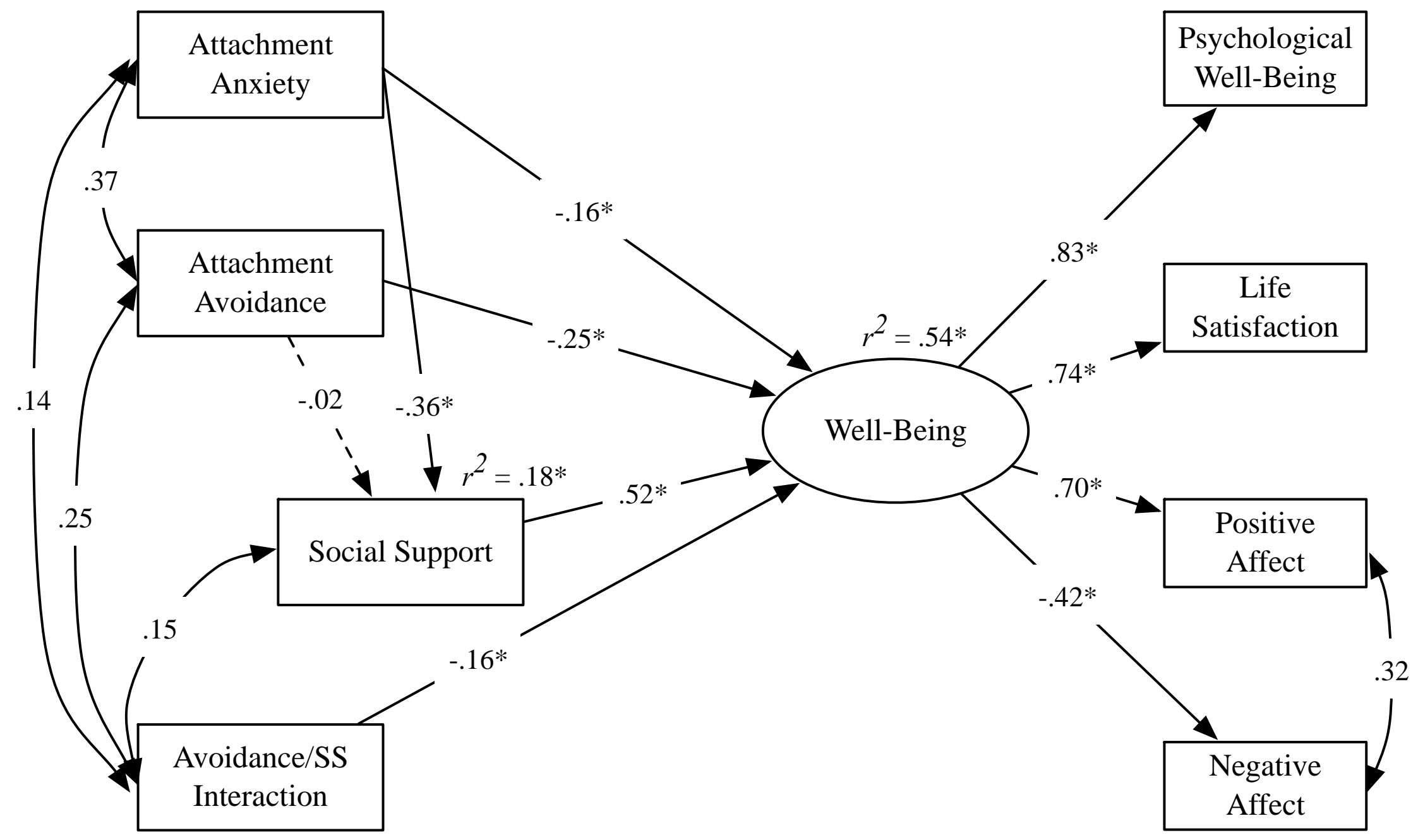

Figure 2. Result of the theoretical model testing. Dashed lines represent nonsignificant parameters. The age and gender covariate variables are excluded from this figure for parsimony. $\mathrm{SS}=$ Social support.

$* p<.01$. 